\title{
Sobre la piel: Reinaldo Arenas y Severo Sarduy en contacto
}

On the skin: Reinaldo Arenas and Severo Sarduy in contact

Na pele: Reinaldo Arenas e Severo Sarduy em contato

\section{Javier Guerrero}

PRINCETON UNIVERSITY, ESTADOS UNIDOS

Profesor asistente de Estudios Latinoamericanos de Princeton University.

PhD, New York University. Sus trabajos inquieren sobre las

intersecciones entre cultura visual, sexualidad, cuerpo y archivo.

Es autor de Tecnologías del cuerpo. Exhibicionismo y visualidad

en América Latina (Iberoamericana - Vervuert, 2014), y editor de diversos volúmenes y libros, entre los que se encuentran Relatos enfermos (Conaculta, 2015), Vulgaridad Capital (Taller de Letras, 2015), Cuerpos enfermos/Contagios culturales (Estudios, 2011) y Excesos del cuerpo (Eterna Cadencia, 2009/2012). Asimismo, es coeditor del libro A máquina Pinochet e outros ensaios (e-galáxia, 2017), antología de artículos y ensayos de la escritora chilena Diamela Eltit. Actualmente, prepara dos nuevos libros: Synthetic Skin: On Dolls and Miniature Cultures y La impertinencia de los ojos: oscuridad, opacidad, ceguera. Correo electrónico:jg17@princeton.edu

Artículo de reflexión

Documento accesible en línea desde la siguiente dirección: http://revistas.javeriana.edu.co doi:10.11144/Javeriana.cl21-42.spra 


\section{Resumen}

A partir de los archivos fotográficos y epistolares que Reinaldo Arenas (1943-1990) y Severo Sarduy (1937-1993) depositan en la Firestone Library de Princeton University, este ensayo aborda las intersecciones entre materialidad corporal, cultura visual y archivo, inscritas en tales colecciones especiales. Así, mediante un minucioso análisis de imagen y letra, y apoyado sobre conceptos tales como plasticidad, cuerpo y materialidad, el ensayo propone un genuino archivo de la piel de Arenas y Sarduy, de las consecuentes narrativas somáticas y de las tecnologías que lo median.

Palabras clave: archivo; materialidad-aspectos culturales; culturas visuales; Severo Sarduy; Reinaldo Arenas

\section{Abstract}

Based on the photographic and epistolary archives that Reinaldo Arenas (1943-1990) and Severo Sarduy (1937-1993) deposited in the Firestone Library of Princeton University, this essay inquires into the intersections between corporal materiality, visual culture, and archive that inscribed in these special collections. Thus, by means of a thorough analysis of images and texts, supported by concepts such as plasticity, body, and materiality, this essay shows a real archive of the skin of Arenas and Sarduy, the subsequent somatic narratives and the technologies that mediate it. Keywords: archive; materialitycultural aspects; visual cultures; Severo Sarduy; Reinaldo Arenas

\section{Se}

\section{Resumo}

A partir dos arquivos fotográficos e epistolares que Reinaldo Arenas (1943-1990) e Severo Sarduy (1937-1993) depositam na Firestone Library de Princeton University, este ensaio inquire pelas interseções entre materialidade corporal, cultura visual e arquivo, inscritas em tais coleções especiais. Assim, mediante minuciosa análise de imagem e letra, e apoiado em conceitos tais como plasticidade, corpo e materialidade, o ensaio mostra um genuíno arquivo da pele de Arenas e Sarduy, das consequentes narrativas somáticas e das tecnologias que medeiam.

Palavras-chave: arquivo; materialidade-aspetos culturais; culturas visuais; Severo Sarduy; Reinaldo Arenas

RECIBIDO: 15 DE JULIO DE 2016. ACEPTADO: 17 DE DICIEMBRE DE 2016. DISPONIBLE EN LÍNEA: 29 DE DICIEMBRE DE 2017

\section{Cómo citar este artículo:}

Guerrero, Javier. "Sobre la piel: Reinaldo Arenas y Severo Sarduy en contacto". Cuadernos

de Literatura 21.42 (2017): 23-48. https://doi.org/10.11144/Javeriana.cl21-42.spra 
LA FOtOGRAFÍA MUESTRA un cuerpo desnudo (figura 1). Con los brazos detrás de la cabeza, alguien posa. La superficie distorsiona el cuerpo, difumina ciertas señas; si se quiere, lo obliga a salirse de sus líneas. El cuerpo se exhibe con aparente comodidad, y hasta desparpajo, colocando entre objeto y objetivo un material que opera sobre él - una mampara de baño, quizá, un lente-. En la esquina inferior derecha, observo un estallido de luz, producto del flash o, más bien, de una fuente luminosa - tal vez una ventana- que se refleja sobre la superficie y que obliga a descartar la posibilidad de un lente o de un efecto de revelado debido a que la fotografía estaría entonces a contraluz, y no es el caso. El cuerpo, entonces, se exhibe detrás de una superficie que redimensiona las formas corporales y produce una materia mediada. Al pensar en este efecto de distorsión, evoco los usos que la contemporaneidad visual le ha asignado; es decir, caigo en cuenta de que hoy día este efecto se emplea para velar la identificación de los cuerpos y proteger el anonimato, pero también para borrar, deformar, volver casi irreconocible un gesto obsceno, un cadáver, una herida desmesurada o ciertas partes corporales de prohibida exhibición. Naturalmente, el efecto constituye una paradoja pues en su deseo de ocultar las zonas irreproducibles, termina señalándolas, enfatizándolas, engrandeciéndolas, las hace aún más visibles y presentes. Sin embargo, esta fotografía no opta por distorsionar ciertas partes del cuerpo sobre otras, sino que decide, por el contrario, velarlo todo, haciendo entonces de él una materia concupiscente, erótica, o si se quiere, obscena. El efecto opera sobre las formas y, en especial, sobre ciertas formas irreductibles para su sexuación; el cuerpo se desnuda, pero el desnudo vela, distorsiona sus marcas sexuales. Asimismo, la superficie de la fotografía y su particular rasgo epidérmico - la textura que genera, este grano que parece dar cuenta de la piel vista por un microscopio- parece inscribir, injertar, entonces, una nueva funda de piel que (me) provoca tocar. El cuerpo se desnuda y la superficie mediadora que lo sexúa y erotiza lo coloca - borrando su sexo, deformándolo, haciendo del pene una mancha ilegible que se deshace de su poder falocrático- en un afuera del sexo. Es decir, la superficie que media entre cuerpo y cámara opera como película que interviene la materia sexuada para prometer un futuro material novedoso. Veo venir un hombre, veo venir un cuerpo, un cuerpo que se resiste a las operaciones del sexo exhibiéndose gozoso. 


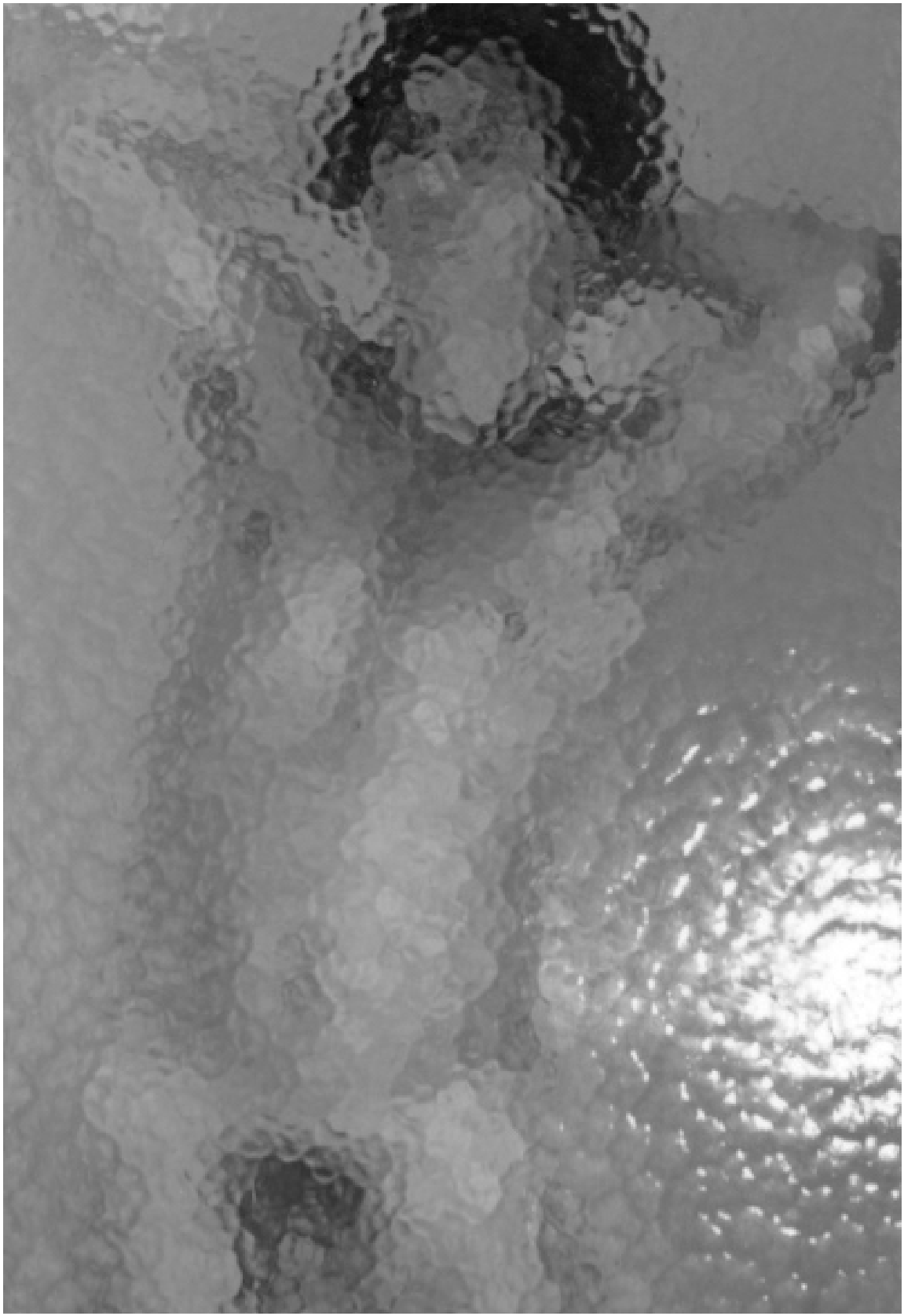

Figura 1. Desnudo de Reinaldo Arenas. Fotografía de Lázaro Gómez Carriles. Nueva York, 1986. Reinaldo Arenas Papers, Box 28 Folder 6; Manuscripts Division, Department of Rare Books and Special Collections, Princeton University Library. 
El cuerpo en cuestión corresponde al del escritor Reinaldo Arenas, fotografiado en 1986 en su apartamento de Manhattan por Lázaro Gómez Carriles. $\mathrm{Y}$ estos datos parten del objeto mismo. Esta fotografía inédita, no reproducida hasta la publicación de mi libro Tecnologías del cuerpo. Exhibicionismo y visualidad en América Latina, pertenece al archivo de Reinaldo Arenas de la Biblioteca Firestone de Princeton University. Se trata de una postal que Reinaldo fabricaba y enviaba a amigos cercanos. Consistía en una fotografía engomada, que él añadía como segunda piel, a una postal cualquiera, que en este caso el escritor cubano le envía a René Cifuentes, compañero de generación sexual y política. La escritura devela el enigma sobre el que discernía. En su reverso, puede leerse el mensaje inscrito: "Niña adorada; aun en los momentos en que me meto bajo la ducha, te recuerdo cálidamente [...]" (figura 2).

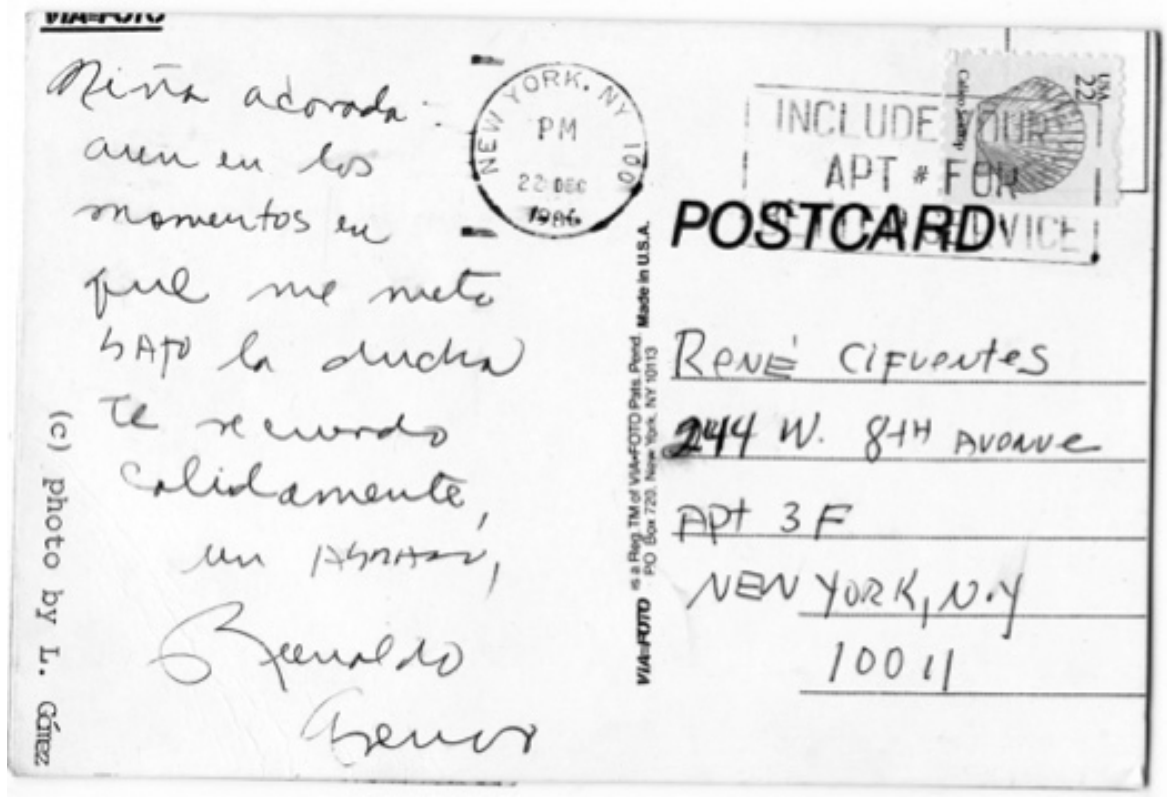

Figura 2. Reverso de la postal enviada a René Cifuentes. Nueva York, 1986. Reinaldo Arenas Papers, Box 28 Folder 6; Manuscripts Division, Department of Rare Books and Special Collections, Princeton University Library.

En esta oportunidad quiero hablar de hombres desnudos, o más bien, de las intersecciones entre materialidad corporal, cultura visual y archivo, y su capacidad de alterar la materia en distintas colecciones de escritores latinoamericanos. Me interesa proponer una zona dialéctica necesaria en la 
que los cuerpos atraviesan una constelación de oposiciones binarias; en todo caso, quiero plantear un lugar de incertidumbre propio de estos archivos de la piel en América Latina. Y me referiré a problemas relacionados con el archivo, la plasticidad y el cuerpo, para entonces abordar las relaciones entre cultura visual y materialidad. Pensaré en la piel de dos destacados escritores cubanos, Reinaldo Arenas (1943-1990) y Severo Sarduy (1937-1993), para aproximarme a la noción de plasticidad de archivo y a las relaciones que ella establece entre cuerpo y materialidad. Estos archivos, ambos ubicados en Princeton University, están conectados con el cuerpo, con su exhibicionismo material como operación estratégica no solo para desorganizar las retóricas nacionales e institucionales, para deshacer las metáforas y alegorías impuestas, sino principalmente para producir y forzar las fronteras materiales del cuerpo y, por lo tanto, del sexo. El archivo es materialidad, exterioridad, y estos escritores se sirven de él para proponer una sustitución corporal, todo un cambio de piel, que aunque a su vez se hace metáfora del cuerpo, tal condición metafórica solo reside en su dimensión material. Es decir, la materialidad de archivo y las narrativas somáticas que la acompañan intentan producir un sustituto que desafía la hegemonía y la fijeza del sexo. No obstante, voy a proponer algo más, un plus, si se quiere. Me referiré a tocar, tocar la piel, tocar el archivo como piel, tocar la piel de archivo como activador de la plasticidad del cuerpo, activando a su vez las íntimas relaciones entre cultura visual, cultura material, cuerpo y archivo.

$\mathrm{Al}$ respecto, ya sabemos por Jacques Derrida que todo archivo es a la vez instituyente y conservador, revolucionario y tradicional: "[a]rchivo eco-nómico en este doble sentido: guarda, pone en reserva, ahorra, mas de un modo no natural, es decir, haciendo la ley (nómos) o haciendo respetar la ley [...] que es la de la casa (ô̂kos), de la casa como lugar, domicilio, familia, linaje o institución" (Derrida, $M a l$ 15). La construcción del archivo a partir de los binomios aparentemente excluyentes obliga a pensarlo en un amplio registro, a lo largo del cual lo único que lo hace verdaderamente archivo es la premisa en la que Derrida insiste: "[n]o hay archivo sin un lugar de consignación, sin una técnica de repetición y sin una cierta exterioridad. Ningún archivo sin afuera" (Mal 19).

No obstante, como ya adelanté, considero que el archivo puede ubicarse en otras zonas dialécticas, es decir, es capaz de trascender la pulsión de muerte y de conservación que esboza Derrida. Y, como plantearé a continuación, esta zona está marcada por la imposibilidad del texto original, la construcción del texto, simultánea a la de un cuerpo, y la plasticidad, como condición constitutiva de este archivo epidérmico. 


\section{La piel de Severo}

Comienzo a abrir este archivo con un experimento. Escribo una carta. Tras tipear y luego imprimir una frase cualquiera, con sumo cuidado procedo a doblar el papel. Con facilidad lo doblo una primera vez. El primer doblez es casi involuntariamente exacto. Lo termino deslizando mi dedo índice, irritando el papel e inscribiendo la rugosidad de una marca. Enseguida volteo el pliego y me dispongo a doblarlo por segunda vez. Esta vez lo hago con las dos manos; deslizando simultáneamente ambos dedos índices, logro una coreografía perfecta que enseguida obtiene el tamaño adecuado, la figura geométrica necesaria para que el papel entre en el sobre. Doblada la carta en tres segmentos ya es capaz de caber en un sobre estándar. Emplazo el sobre de cabeza, y ahora ensalivo ligeramente mi dedo índice, lo deslizo por la banda engomada del propio sobre. Lo cierro. Para garantizar que esté sellado vuelvo a la coreografía anterior, esa en la que los dos dedos se mueven en perfecta sincronía. Lo sello y enseguida volteo. Acaricio la cara frontal del sobre con una de mis manos como preparándolo para la escritura. Entonces procedo a irritar el papel nuevamente, esta vez con la punta de una pluma negra. Escribo sobre él.

Con este experimento me interesa dar cuenta de las veces que toco la carta. Pese a que la máquina de escribir o, en este caso, la computadora, produce una separación artificial entre mano y papel, interrumpe la continuidad del cuerpo y el soporte con una prótesis, replicándole al contacto irresoluble de todo manuscrito, mi experimento da cuenta de la necesidad de tocar una y otra vez el papel. La carta es un cuerpo acariciado, irritado, ensalivado que luego de pasar por mis manos y pasar de mano en mano, llega con suerte a su destinatario, quien la acaricia, al leerla y al releerla para luego volver a doblarla, casi siempre reproduciendo el mismo movimiento que la originó. En este caso, en toda correspondencia se inscribe un discurso amoroso. Las manos tocan el objeto, el papel que el destinatario a su vez tocará. El sobre inscribe el pacto de exclusividad amorosa propio de la carta de amor. El sobre que la contiene y que por supuesto forma parte de la correspondencia constituye la cáscara que la resguarda, su traslúcida coraza. La carta deberá ser tocada casi exclusivamente por su remitente y su destinatario. Y, tal como sugiere Roland Barthes al proponer que toda carta de amor obliga implícitamente a su destinatario a responder (52): el simple envío de una carta amerita su reciprocidad, una correspondencia.

La colección de Severo constituye un archivo-relato en el que el cuerpo cobra especial relevancia. Abordaré cartas de un viajero cuya extranjería, 
como podrá comprobarse más adelante, se desarrolla en una dirección distinta a la de Reinaldo Arenas, pese a ciertas circunstancias que se repiten. Me centraré en esta colección adquirida por la Universidad Princeton a fines de agosto de 2014. La colección consta de más de mil cartas enviadas por el escritor a su familia desde su salida de Cuba, en diciembre de 1959, hasta su muerte, en 1993. En los primeros años fuera de casa, de 1960 a 1965, Severo escribe semanalmente a sus padres y a su hermana Mercedes, en cuyas cartas hace una crónica pormenorizada de su vida cotidiana.

En una correspondencia de 1974 desde Saint Léonard, Severo Sarduy escribe: "[u]n editor español va a publicar no un libro mío, sino un libro entero sobre mí. Es la primera vez que esto ocurre y la colección [...] es una de las más populares [...] Estoy redactando la biografía, que comienza, naturalmente, el 25 de febrero de $1937 " .{ }^{1}$ No obstante, Severo propone una operación a la que me quiero referir: "[...] se me ha ocurrido una idea para cambiar un poco el modo tradicional de las biografías. Creo que hay que hablar de lo que pasó antes de ese 25 de febrero y también de lo que pasará después de la publicación de la biografía" (Sarduy, M. 27).

De este extracto deseo señalar dos cosas. Por un lado, la distinción entre "un libro mío" y "un libro entero sobre mî"; distinción en la que saltan a la vista el uso del adjetivo "entero", que implica totalidad, y el uso del complemento "sobre mí", al que más adelante me referiré, ya que vuelca la condición de autor; por otro lado, me interesa la temporalidad que opera en la noción biográfica de Sarduy, temporalidad que sugiere entender la vida fuera de la maquinaria biológica al inscribir un futuro no del todo probable. En relación con esto último, en lo que sigue, quiero ir precisando algunos aspectos. Severo Sarduy pide a sus padres que cooperen en esta "obra colectiva", específicamente escribe: "les pido a mamá y a papá que me redacten cada uno una o dos páginas sobre cómo se conocieron, etc. Con detalles de época, cómo eran los trajes, qué música se oía, qué costumbres se usaban, etc." (Sarduy, M. 29). Llama de inmediato la atención que el encargo comience con la solicitud de "una o dos páginas", lo cual, pese a lo anecdótico, ya da cuenta de cierta materialidad a la que más adelante me referiré. Pero lo que

1 Aunque la correspondencia citada en este artículo proviene, en su mayoría, del archivo de Severo Sarduy en la Universidad de Princeton, algunos apartes se extrajeron de Cartas a mi hermana en La Habana, un libro publicado en 2013 por Mercedes Sarduy, en el que transcribe fragmentos de algunas cartas familiares de Severo. 
no explica Severo en el resto de la carta es cómo inscribirá "lo que pasará después de la biografía", este futuro inscrito en la vida escrita del escritor. Y considero que la inscripción del futuro será un punto fundamental para leer la colección de Severo. Sin embargo, para ello debo primero detenerme en la muy temprana triangulación que la correspondencia familiar establece entre cuerpo, objeto y sí misma.

Para llegar a España, desde La Habana, Sarduy toma un barco, el Marqués de Comillas, que antes de emprender el viaje transatlántico hace una parada en Curazao y otra en el puerto de La Guaira, Venezuela. Severo envía dos cartas y una postal que resumen el viaje de 19 días. El primer objeto que envía es una fotografía, la cual se produce precisamente en Venezuela (figura 3). En la presunta fotografía que anexa, se ve a Severo en La Guaira. En la carta dice: "[a] las ocho de la mañana llegamos al puerto, pero como la calma venezolana es algo increíble, y el despachador de visa no se alteraba de nada, alternando una copita entre visa y visa, salimos del barco a las 10:30" (Sarduy, M. 169). Esta fotografía inaugurará toda una constelación de relaciones que perpetra el archivo en relación con el cuerpo. Tras su llegada a España y su casi inmediata mudanza a París, además de la minuciosa crónica diaria que el escritor relata para su familia y de la continua referencia a obras de artes, paisajes, películas, Severo escribe con recurrencia sobre su cuerpo. Apenas a dos meses de su partida, el escritor le envía una carta a su familia, a la que anexa una fotografía: "[e]stoy muy bien, me encuentran gordo, sobre todo ahora que me pelé cortísimo ya que estaba atacado del pelucón". Las cartas prosiguen dando detalles de su pelo, su peso y, en especial, de los cambios que experimenta. En julio de 196o, escribe "[e]nviaré fotos. ¿Verdad que me estoy poniendo buenmozo?"; en agosto del mismo año, escrito en un talón de cambio de divisa, le pregunta a su madre: "[ $\left.{ }_{\mathrm{c}} \mathrm{d}\right]$ ime si no estoy gordo?" y el 11 de septiembre afirma: "[c] omo verán por la foto que adjunto yo estoy muy alto". Pero ante la presunta apatía de la familia en relación con su cuerpo, Sarduy escribe con severidad: "[1] es adjunto mis dos últimos poemas, esperando crítica, asimismo como comentarios de mis fotos en la Plaza San Marcos y en la Fuente de Trevi" (París, 16 de octubre de 1960). Lo que parece interesarle a Severo es precisamente la opinión de su familia, en especial las de su madre y su hermana, acerca de su muy acelerada transformación corporal. Y resulta llamativo que las cartas del escritor cubano no solo expongan su cuerpo, lo relaten y citen las fotografías para dar cuenta de su transición, sino, principalmente, que interpelen, una y otra vez, a la familia e incluso casi la obliguen a 
confirmar su percepción y, en cierto sentido, a participar colectivamente en la narración y - como plantearé más adelante-materialización de sus formas.

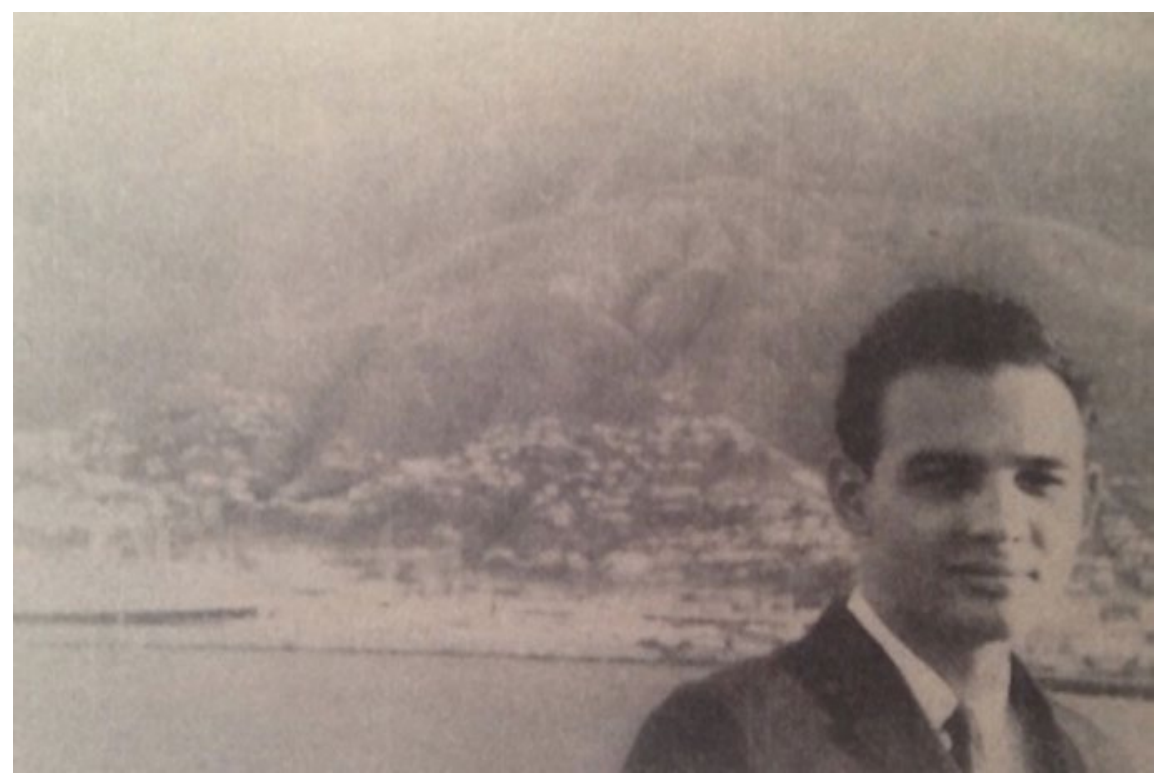

Figura 3. Severo Sarduy en La Guaira, Venezuela. Diciembre de 1959. Colección privada de Mercedes Sarduy.

A poco más de un año de su partida, Severo afirma con un entusiasmo que parece no poder ocultar: "[y]o estoy encantado de la vida, muy bien, muy gordo, muy calvo, hablo y escribo en cuatro idiomas". El 24 de septiembre de 1960, afirma: "[e]sta foto es como esos acertijos que ponen en las revistas de niños que dicen "Vamos a ver quién encuentra el cochinito"'. Estas cartas en las que hace referencia a los cambios del cuerpo abundan, y resulta relevante cómo la fotografía, utilizada en la correspondencia como prótesis visual que completa la letra y que no la precede sino prosigue, constituye un aparato ficcional que le permite inscribir su trasformación. Es decir, en las cartas la fotografía no funciona más como índice del cuerpo, por el contrario, se vuelve materia flexible sobre la que se modela su futuro, el futuro del cuerpo. Es como si la letra de la correspondencia escrita fuera capaz de modificar la imagen. Para ello, Sarduy necesita exhibirla y que sus familiares den "el visto bueno", confirmen los cambios de Severo en el extranjero. Un procedimiento adicional resulta esclarecedor. En marzo de 
1961, el escritor relata que en breve recibirá veinte fotografías. No obstante, antes de contar con ellas y de proceder a enviarlas a su familia, decide anexarle a esta una que ya posee y sobre la que escribe: "les suplico no [la] peguen en el álbum ya que quedé horroroso con un ojo más pequeño que otro, pero en fin, podrán apreciar los sesenta y cinco quilos de peso y el avance de la calvicie, que desde el punto de vista físico son los dos progresos más sobresalientes del año". Aunque por supuesto la carta no esconde su tono humorístico, el hecho de enviar una fotografía sobre la que se dibuja otra silueta - incluso una silueta monstruosa dada la asimetría del cuerpoque pide no inscribirse en el álbum familiar resulta revelador. En cierto sentido, desde el mismísimo primer año fuera de Cuba, Sarduy desarrolla una transformación que le permite separarse de la narrativa y las formas familiares, una transformación que además de ser anecdótica, anécdotas sobre las que regularmente sospecho, apunta a problemas más complejos. Y esto parece producirse para ocupar otro espacio, un cuerpo des-inscrito materialmente de las fábulas familiares. No obstante, una vez más, este procedimiento resulta contradictorio debido a que esta autonomía material que cobra el archivo, paradójicamente depende de ser vista para ser inscrita; es decir, la familia, como destinataria de este espectáculo somático, debe confirmar lo que Sarduy, su remitente, relata, y a su vez, ver esto - fijarlo, si se quiere - en las fotografías. Las fotos de Sarduy, las múltiples transformaciones corporales que narran las cartas y sus prótesis visuales, inscriben una discontinuidad, un hiato en el álbum familiar heteronormativo.

Asimismo, en este proyecto, vale la pena percatarse de cómo el archivo no solo da cuenta de la extranjería del cuerpo y de las transformaciones que comienza a experimentar en el extranjero, sino también de las posibilidades transformativas que incluso la moda, la francesa por ejemplo, y las tecnologías cosméticas logran producir: "[o] tro tópico: moda francesa. Cuello jirafa y sombrero de caja de queso" (París, 30 de enero de 1961) o "[¿q]uerrán saber el último grito de París? Peinados decorados con mariposas y pinturas que armonizan con la de los vestidos" (12 de diciembre de 1960). El archivo da cuenta de cómo, desde París, Severo reporta las posibilidades cosméticas de transformación que luego se radicalizarán. Aparece entonces el objeto. Es decir, reaparece, se duplica, porque la correspondencia ya lo es. A las cartas se anexan objetos que atraviesan el Atlántico para llegar hasta las manos de sus familiares. Precisamente estos objetos están íntimamente relacionados con el cuerpo o con la propia materialidad de la correspondencia que, como propondré al final de este artículo, produce una tautología material. Severo 
Sarduy envía una mantilla a su madre, un suéter y un "verdadero Dior" a su hermana, entre otras prendas u objetos autorreferenciales de la correspondencia, sellos postales, por ejemplo. Pero uno de los objetos sobre los que más enfatiza y con el que crea todo un relato es un pañuelo, un pañuelo de Pablo Picasso. A pesar de los muchos objetos que Sarduy le envía a su familia, me detendré únicamente en este, debido a su capacidad de condensar el papel del objeto en esta correspondencia familiar. En carta del 17 de junio de 1960, Severo Sarduy escribe:

Hoy pongo también en el correo, por barco, un pequeño paquete que contiene un pañuelo de Pablo Picasso. Es uno de los originales de una edición absolutamente limitada que se hizo en su visita a Moscú, en el 57 . Él se lo dio, en prenda de amor, a Gracia Ganzó [...] Tiene dibujada una paloma de la paz, vestida con cintas rojas y azules [...] Este es su tercer destinatario. Y su tercera misión de amor [...] Quizá pronto te envíe un fragmento de la novela que comienza precisamente con una descripción exhaustiva (muchas páginas) de este pañuelo.

El objeto que envía no solamente propone el encadenamiento amoroso que ya sugería Barthes - la posibilidad de este pañuelo de pasar de "mano en mano"-, sino que, en este caso, el pañuelo de Picasso superpone objeto y texto. Es decir, entrelaza a partir de la materialidad del objeto, la materia de la escritura. Interesantemente, Sarduy reproduce una operación que sella su poética, es decir, que desnuda la manera en que se produce un texto. En una entrevista, el escritor discute este mismo movimiento. Comienza planteándose que si se tratara de discernir lo que ocurre en el momento de la escritura, tendríamos que intentar definir lo que ocurre en el momento de la generación del texto (en cierto sentido un pretexto). Al respecto, Severo confiesa que es este, quizá, el único momento que le resulta totalmente oscuro:

$[\ldots]$ para mí, la conciencia mecánica del texto o su factura [...] está claro [sic], pero hay un momento de ceguera, yo diría de obturación total en su generación, que no logro discernir. Es quizá en ese momento que una frase o un color, o casi siempre un cuadro, incluso una persona en tanto que imagen van a generar el texto. En la teoría de Lezama Lima, la imagen tiene una función generadora [...] Sin embargo, en Lezama la imagen está dotada de lo que él llama una sustancia devoradora, que la hace agrandarse hasta constituir una totalidad de conocimiento. Yo creo que [...] lo que yo hago es al contrario, no creo que la imagen vaya devorando, yo creo que más bien la imagen está adherida a algo que va a ser la escritura. (Sarduy, M. 76-77) 
Esta imagen en Severo Sarduy tiene que ver entonces con la materialidad de un objeto o un cuerpo que en las cartas a la familia del archivo queda al desnudo. No se trata de una imagen desencarnada, como él mismo parece explicar en un principio, es la materialidad del objeto adherida al papel, la que deviene entonces materia escritural y por lo tanto materia plástica; a esta plasticidad voy a volver más adelante.

La triangulación sarduyana entre texto, objeto y cuerpo está íntimamente ligada a su concepto de simulación, que el artista cubano relaciona con el travestismo. Sarduy define su concepto de simulación en cuanto que

La mariposa convertida en hoja, el hombre convertido en mujer, pero también la anamorfosis y el trompe-l'oeil, no copian, no se definen y justifican a partir de las proporciones verdaderas, sino que producen, utilizando la posición del observador, incluyéndolo en la impostura, la verosimilitud del modelo, se incorporan, como en un acto de depredación, su apariencia, lo simulan. (Sarduy, Simulación 19)

La posición del observador para hacer posible esta simulación es fundamental como ya propuse en el caso de Sarduy con su familia, la de ver de una manera, desde una posición, la fotografía. Para esta poética entonces tanto el animal como el travesti - sigo el uso de Sarduy de la palabra travestino buscan una apariencia amable para atraer o una apariencia desagradable para repeler, sino más bien una incorporación de la fijeza para desaparecer (Sarduy, Simulación 16). Y esta desaparición - que usualmente Sarduy inscribe en itálicas, probablemente por constituir una dimensión enigmática, oscura - resulta clave para el sistema que estas cartas, como ya he sugerido, desnudan. En cierto sentido, la incorporación de objetos (fotografías o demás prendas de vestir), así como la escritura producen una tautología material todos enfatizan su materialidad debido a que son citados para cumplir este cometido - que precede y prosigue a la imagen. Es decir, la imagen aparece encapsulada por la materia y por lo tanto se deshace. He guardado la parte final del relato del pañuelo de Picasso para este momento, ya que las últimas oraciones de la carta proponen algo definitivo. Sarduy prosigue su narración: "el vuelo de la paloma dibuja, a un lado y al otro del mismo, el rostro de los dos personajes principales, es decir, de los dos observadores, ya que la novela no trae personajes y su protagonista es la multitud". Objeto, carta y cuerpo se funden. Y es el objeto viajero el encargado de encadenar este trío.

Asimismo, desde temprano, Sarduy construye lo que más adelante descubrirá como el centro de las grandes teogonías orientales: "no una presencia 
plena, dios, hombre, logos, sino una vacuidad germinadora cuya metáfora y simulación es la realidad visible, y cuya vivencia y comprensión verdadera son la liberación" (Simulación 20). Si la vacuidad, entonces, resulta germinadora, y su simulación constituye la imagen, entonces su desciframiento (comprensión, vivencia) es una vez más un nuevo desplazamiento, aunque no retorno, a la vacuidad. Por lo tanto, la imagen también funciona de manera prostética en cuanto a que es y está encapsulada, precedida y proseguida por la vacuidad o, por lo menos, por esa zona inexplicable pero que no depende de la imagen o constituye la imagen de por sí: lo que más bien es una ceguera.

Precisamente, cuando Sarduy indaga en el trompe-l'oeil, afirma que el tacto es el sentido que tiene que venir a comprobar y a desmentir lo que la mirada, que Severo describe como "víctima de su ingenuidad", da por cierto. "Los dedos anulan de golpe la falsificación [...]" (Simulación 41). Entonces, toda la orquestación o, más bien, la constelación queda desmantelada pero no perdida con la posibilidad de tocar: "el trompe-l'oeil, más allá del paso del ojo a la mano, da testimonio de lo que hay de surplus a la representación de toda presencia" (Severo, Simulación 53). Soporte y representación se reducen estratégicamente a cero, siendo este paradójicamente su exceso.

A propósito de esto último, en "Escrito sobre un cuerpo", Sarduy discute la novela Compact, del escritor francés Maurice Roche, en un texto que titula "La aventura (textual) de un coleccionista de pieles (humanas)"; Severo afirma:

La literatura es $[\ldots]$ un arte del tatuaje: inscribe, cifra en la masa amorfa del lenguaje informativo los verdaderos signos de la significación. Pero esta inscripción no es posible sin herida, sin pérdida. Para que la masa informativa se convierta en texto, para que la palabra comunique, el escritor tiene que tatuarla, que insertar en ella sus pictogramas. (1154)

Sarduy encuentra en esta novela su propia poética. El final de este segmento, que subtitula "El libro por venir" - relevante subtítulo a propósito de la presente lectura-, sospecha que la novela de Roche no sea un hecho aislado sino más bien uno de los trabajos inaugurales de una nueva literatura en la cual el lenguaje aparezca como el espacio de la acción de cifrar, como superficie de transformaciones ilimitadas: "[1]iteratura en que todas las corrientes, no del pensamiento sino del lenguaje que nos piensa, se harían visibles, confrontarían sus texturas en el ámbito de la página" (Sarduy, "Escrito" 1154). La erupción de la página en este fragmento da cuenta de la materialidad de esta como síntesis de la materialidad del cuerpo y en especial de su capacidad de transformarse, su capacidad ilimitada de transformarse. 
Las cartas de Severo Sarduy, enfatizadas por sus relatos sobre el cuerpo, demuestran lo que en cierto sentido toda carta produce: un contacto material. En el experimento con el que inicié la lectura de este archivo, no solo quise proponer la cantidad de veces en que a pesar de la maquinaria prostética que constituye la máquina (o incluso la pluma) tocamos el papel, sino el hecho de que toda carta implica el deseo de tocar al otro - y aquí, naturalmente, también podríamos pensar la máquina o la pluma como prótesis del cuerpo-. Es en el papel donde se produce este tocar. En él se produce una síntesis, una tautología material, una saturación.

En una carta de 1960, Severo se excusa ante su familia por no escribir mucho para tal ocasión, afirma que: "el dolor que/da teclear en la punta de los dedos es horrible". No obstante, en esta carta se produce un error, un typo - como diría en inglés - interesante. Severo escribe "queda"; por error, la preposición y la conjugación en tercera persona singular del verbo dar se unen y ofrecen una nueva frase, "el teclear queda en la punta de los dedos". Los dedos, tras el error inscrito / tatuado en la página en blanco, traspasan entonces - como si quisieran traspasar la frontera material del cuerpo y viceversa-. Los dedos se incrustan en el papel y allí se quedan.

Para Sarduy, el travesti, como la mariposa - y aquí quiero también incorporar ese peinado francés adornado con mariposas al que se refería el escritor cubano-, modifican su organismo, hacen del cuerpo su propio soporte y producen lo que define como "autoplástica", que yo más bien, en el contexto de este artículo, quiero plantear como una autofagia, ya que en la plasticidad nunca hay una autonomía total. El libro por venir, de Roche, con el que Sarduy cierra este capítulo de "Escrito sobre un cuerpo" interpela. Más que el libro por venir pienso en el por venir libro. El procedimiento de Sarduy, sus cartas familiares como germen de todo su pensamiento estético, es entender que la simulación de la correspondencia constituye el primer ensayo del cuerpo. Y es que las posibilidades de transformar el cuerpo y sellar otras corporalidades están íntimamente relacionadas con la ficción y con la triangulación de la materialidad en el papel escrito.

Pero debo apuntar una cosa más. Al referirme al experimento de la biografía, aquella que pedía la participación de sus padres, propuse que Severo Sarduy rompía la frontera biológica del cuerpo; no solo la frontera previa, la que ocurre tras su nacimiento, sino principalmente en relación con el futuro, con el porvenir del cuerpo. El experimento se perpetra. En 1976, se publica el texto biográfico, una especie de cronología que comienza de la siguiente manera: "[s]e veían a lo lejos las luces de un bazar repleto de juguetes", y Sarduy finaliza " $[\mathrm{s}] \mathrm{i}$ adoptaron dioses o águilas y mimaron sus ritos hasta la idiotez o 
el hastío fue para demostrar - dicen ahora - con su propio ejemplo, la impermanencia y la vacuidad de todo", última línea que versiona el final de su novela Maitreya (689). Palabras finales del surplus de esta biografía. Este ejercicio de inscribir en el cuerpo el futuro, inscribe a su vez el movimiento final de Sarduy y de sus cartas, y de sus objetos. "La impermanencia y la vacuidad de todo" inscrita en la página.

\section{La piel de Arenas}

Ahora procederé a abrir el archivo de Reinaldo Arenas en Princeton University. Es decir, comienzo a abrirlo. Activo el proceso de apertura debido a que aún estoy lejos de las cajas que contienen los objetos, fotografías, documentos de Reinaldo Arenas. Se trata de una tecnología de archivo que activo desde mi oficina, digitalmente, desde cuya ventana puedo ver el edificio de la Biblioteca Firestone (figura 4). Diría que casi puedo tocar el edificio, pero no lo puedo hacer. Me dirijo a él, entro. Abro el locker disponible. Guardo allí mis pertenencias; dejo parte de mi ropa, cierro y me quedo entonces con lo mínimo. En cierto sentido, me desnudo un poco. La persona a cargo me pide la identificación, registra la orden que he hecho y la inserta en un contenedor plástico que encapsula mi identificación para, entonces, colocármela en la camisa: debe permanecer visible durante mi estadía en el área de Rare Books and Special Collections. Luego, me pide que pase al baño para lavarme escrupulosamente las manos. Lo hago. Salgo inmediatamente y camino hasta la sala de consulta. Allí me siento y otra persona me pregunta con cuál caja deseo comenzar. Digo, de memoria, la número 27. Enfatizo, la 27, por si no me ha oído o mi inglés de segunda mano ha generado un ruido. Enseguida, la persona viene con un carrito parecido al que usan los hoteles para el room service y me entrega la caja. Antes de tocarla debo firmar el recibo y, con gentileza, me alcanza una hoja agujereada color naranja, un lápiz y un marcalibros extra large hecho con material libre de ácido. Toco entonces la caja. Inserto el marcalibro. La abro (figura 5). Una fotografía de Reinaldo Arenas solicita mi mirada. Una en la que Reinaldo, fotografiado por Néstor Almendros, parece un lobo. Los ojos oscurecidos, la mandíbula pronunciada, animal, su cabello indomable. Siempre me ha parecido que en esta fotografía su cara logra una forma inédita. El lente usado lleva a acercarnos demasiado a la piel de Arenas. Las arrugas prematuras de los ojos, las venas del cuello, las marcas biográficas, sus poros. Se trata de una fotografía de 1981, Reinaldo recién llegado de Cuba. En especial, destaca la textura epidérmica. Más que una fotografía de Reinaldo, se trata de la fotografía de la piel de Reinaldo. Su porosidad, su textura de arena. Por supuesto, la piel de Reinaldo, que es Reinaldo (figura 6). La toco e imprimo enseguida mi huella. Separo el dedo para ver cómo mi huella lenta- 
mente se desvanece sobre el papel fotográfico, sobre la piel de Reinaldo Arenas que también es la piel de la foto. Al tocarla me doy cuenta de que he abierto el archivo.

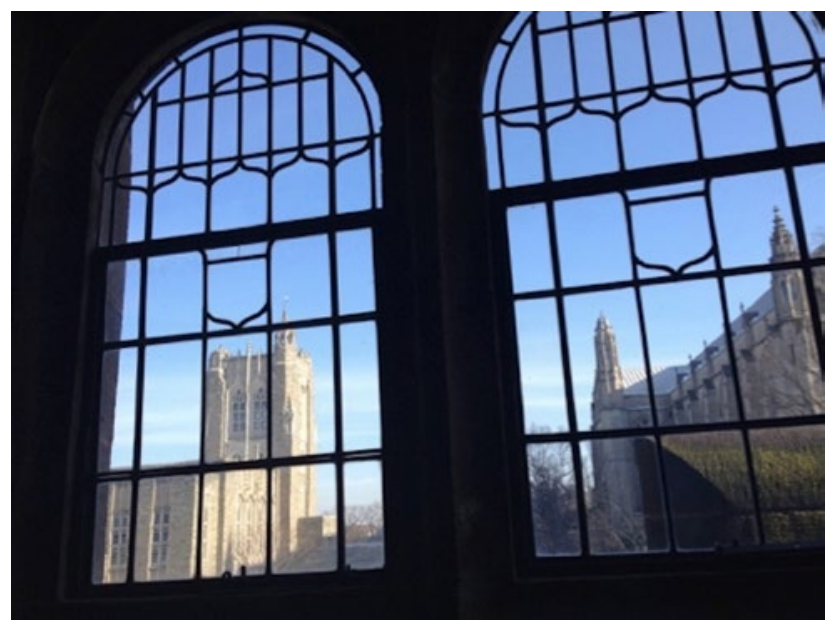

Figura 4. Desde la ventana de mi oficina. Firestone Library, Princeton University. Fotografía de Javier Guerrero, 2013.

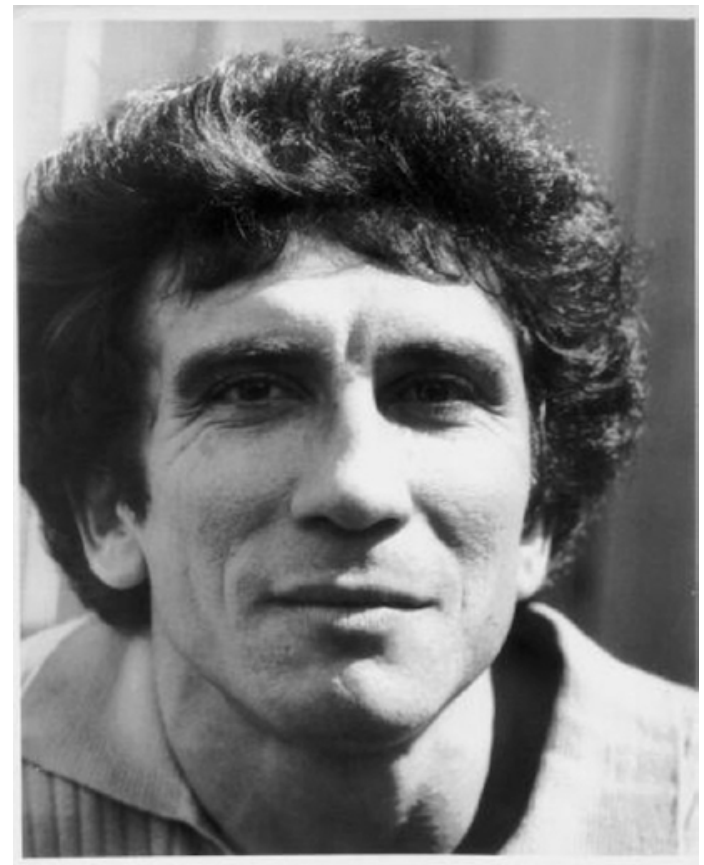

Figura 5. Reinaldo Arenas. Fotografía de Néstor Almendros. Reinaldo Arenas Papers, Box 27 Folder 3; Manuscripts Division, Department of Rare Books and Special Collections, Princeton University Library. 


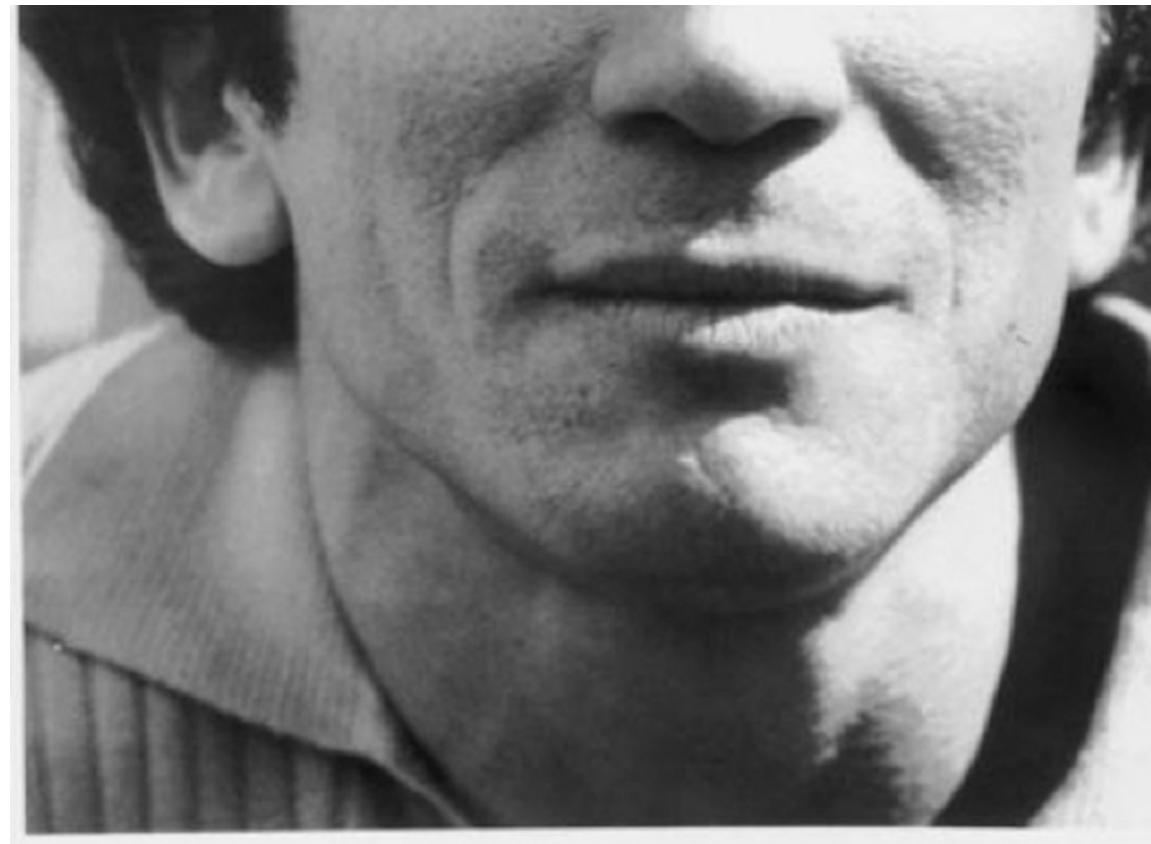

Figura 6. Reinaldo Arenas. Fotografía de Néstor Almendros. Reinaldo Arenas Papers, Box 27 Folder 3; Manuscripts Division, Department of Rare Books and Special Collections, Princeton University Library.

La Universidad de Princeton es el lugar escogido por Reinaldo Arenas para depositar la "textualidad" y plasticidad de su cuerpo. En el Departamento de Rare Books and Special Collections de la Biblioteca Firestone - sintomática ubicación - se encuentran veintiocho cajas contentivas de materiales relacionados con Reinaldo Arenas. Codificado como Co232, el archivo consiste en una recopilación de trabajos y documentos personales en el periodo abarcado entre 1968 y 1990. Consiste en 28 cajas archivadoras, subdivididas en carpetas libres de ácido, entre las cuales se encuentra un borrador mecanografiado de su novela inédita titulada ;Qué dura es la vida! (1959). $\mathrm{El}$ archivo está dividido en cuatro grandes partes y es de consulta pública, pero tiene un par de restricciones que ya caducaron: la correspondencia de Oneida Fuentes (madre de Reinaldo Arenas) no podía ser consultada hasta después de su muerte, sucedida en 2010, y el original mecanografiado de $A n$ tes que anochezca; pese a que Reinaldo Arenas lo cerró por 20 años después de su muerte, continúa restringido. 
Quiero comenzar enfatizando en la obsesión de Reinaldo Arenas con su archivo. No solo es un proyecto personal que lleva a cabo en vida, sino que el mismo se convierte, ante la paranoia del cubano, en el único espacio que garantiza la supervivencia de los originales — dadas las confiscaciones y las repetidas pérdidas de sus manuscritos en Cuba-. Y aquí justamente se construye la paradoja que recién señalaba. El archivo Reinaldo Arenas es una escenificación de la reescritura, una puesta en escena de la repetición. La compulsiva corrección, ligada sin dudas a la re-escritura, se torna más notoria al organizar y depositar cada uno de los borradores. Esta puesta en escena que emplea el archivo constituye una negación de lo definitivamente escrito como expresión del original fetichizado, sinónimo de lo acabado, principio de la escritura, y por lo tanto una consciente pero fatal preferencia por la reescritura como tránsito, como paradoja material de lo inacabado. La paradoja radica en que los originales de la escritura siempre son reescritura, pérdida, tránsito. En la mayoría de los libros de Reinaldo Arenas se repite una nota que advierte: "Los textos originales [...] forman parte de la colección de manuscritos de Reinaldo Arenas de la Universidad de Princeton, Nueva Jersey, donde pueden ser consultados". Por lo tanto, este llamado a examinar los originales produce, siendo esta mi primera lectura, una performance: la única certeza al enfrentarse con la colección radica justamente en renunciar a los originales, enfrentar la ausencia, su imposibilidad, lo cual a su vez testifica un paralelismo presente en el trabajo del escritor cubano: la inexistencia de los originales sexuales.

En la obra de Reinaldo Arenas, la relación entre textualidad y cuerpo no es solo relevante sino también compulsiva. En Celestino antes del alba, primera novela de Arenas, luego de que el abuelo derriba a hachazos los árboles en los que Celestino ha escrito sus poemas, el narrador - doble de Celestino-dice: "[h]achas. Hachas. Hachas [...] Y yo tengo un miedo enorme de que algún día a Celestino le dé la idea de escribir esos garabatos en su propio cuerpo" (89). Asimismo, en sus memorias, Arenas confiesa que $E l$ mundo alucinante hablaba de un fraile que había pasado por varias prisiones sórdidas, entre ellas la de El Morro, y cuando Reinaldo entró a la cárcel, allí decidió que en adelante tendría más cuidado con lo que escribiera, porque parecía estar condenado a vivirlo en su propio cuerpo (222). De manera semejante, la relación entre reescritura y cuerpo resulta relevante. La censura de sus libros, que lo lleva a reescribir toda su obra, se asocia con su visibilidad y su cuerpo. Cuando en 1981, el mismo año de la fotografía de Almendros, Reinaldo Arenas vio por primera vez las bóvedas en las que se custodiaban 
las colecciones de Princeton, sintió que estaba a salvo. Este archivo albergaría entonces las múltiples reescrituras de las obras perdidas o confiscadas en Cuba, archivo fantasmático en cuya arena estarían depositados los originales extraviados, malditos, imposibles. A partir de este momento, como ya mencioné, todos sus libros llevan una inscripción que invita a los lectores a revisar los "originales" en el archivo de Princeton University. En mi libro, Tecnologías del cuerpo. Exhibicionismo y visualidad en América Latina, leí este gesto como una performance en la que el texto nos envía tras los originales para entonces atestiguar su inexistencia, pero en esta ocasión quiero sospechar de esta primera lectura o, por lo menos, añadir otra. La misma está relacionada con la noción de plasticidad que la filósofa francesa Catherine Malabou ha desarrollado en los últimos años.

El archivo tiene que ver con el exceso. Los archivos de escritores usualmente incluyen lo que está fuera, lo que está de más, lo impublicable, lo que de alguna manera excede las formas finales. El archivo entonces es un espacio que contradice la obra de los artistas. Esto sucede, en especial, en aquellos archivos latinoamericanos maricas en los que el cuerpo se inscribe como forma alterable, capaz de transformarse póstumamente dentro del propio archivo. Malabou entiende que la afirmación dominante de la filosofía de Hegel reside en que la subjetividad nunca es pasiva; no es una instancia fija y sólida, es por el contrario una instancia plástica. Como la cera, la subjetividad es receptiva y donadora de su propia forma. Para Malabou, la plasticidad caracteriza la relación que el sujeto mantiene con el accidente; visto por Hegel, este accidente tiene una doble contextura: como predicado lógico (accidente de una sustancia) y predicado cronológico (el acontecimiento). Es decir, Hegel ejecuta la plasticidad del propio término de plasticidad. Entonces, la plasticidad designa todo aquello que se relaciona con la emergencia de la forma: tanto en francés como en alemán, la palabra "plasticidad" aparece históricamente después del adjetivo (plástico), por lo cual, la misma está situada entre el modelado escultórico y la deflagración. Entonces, el surgimiento de una forma, es decir de un accidente, es al mismo tiempo la posibilidad de aniquilación de dicha forma. La forma es sin duda más que presencia. Malabou descubre que en Hegel la forma está pensada en la coincidencia entre el surgimiento y la explosión de la presencia y este descubrimiento abre la posibilidad de un nuevo materialismo.

Malabou encuentra en la filosofía de Hegel, la doble connotación que advierte a propósito del adjetivo "plástico". Por un lado, Hegel se refiere a "personajes plásticos" (Pericles, Fidias, Platón, entre otros) que le dan forma 
al "espíritu en su cuerpo" (Malabou, "Future" 205). Por el otro, una segunda connotación del término en Hegel se da en el término "discurso plástico", en el que la autodeterminación se produce tras "excluir rigurosamente la relación común entre las partes de la proposición [filosófica] [...] como proceso de 'autodeterminación' de la sustancia". Es decir, la sustancia posee en sí misma la capacidad de ser y de dar forma, lo cual constituye la "operación originaria de la plasticidad" (Malabou, "Future" 207).

Para distinguir la "estructura anticipatoria" que opera en la subjetividad tal como es concebida por Hegel del concepto de tiempo, la filósofa crea un nombre "le voir venir", en español, "ver venir", que contiene en sí mismo una dialéctica. Es una expresión que simultáneamente se refiere a estar seguro de lo que viene y no saber lo que se acerca. Jacques Derrida sostiene que uno de los grandes aportes de Malabou radica en la intersección filosófica entre la expresión "voir venir" y la plasticidad, ya que ambos términos dialécticamente conjugan el tellos y la sorpresa, la anticipación y la erupción, la metamorfosis y la explosión absoluta (Malabou, Future xvi).

En cierto sentido, esta coincidencia entre el surgimiento y la explosión de la presencia, entre el modelado y la deflagración, se relaciona tanto con la noción de archivo como con la propia historia de la construcción de este archivo, el de Reinaldo Arenas. Todo empieza con una invitación al escritor cubano a Princeton en 1981. Sylvia Molloy, para entonces profesora del Departamento de Romance Languages, invita a Reinaldo y, a propósito de su visita, organiza un encuentro entre el escritor y el bibliotecario especialista en cultura latinoamericana, Peter Johnson. Poco después, se celebra el contrato. Pero es a partir de 1987 cuando se acelera, se vuelve más activa y urgente la incorporación de materiales en el archivo. La cubana María Badías, amiga de Reinaldo Arenas, relata que en el verano de 1987, Reinaldo sabía que estaba enfermo: "Rey no se lo admitía ni a sí mismo. Era un hombre orgulloso. Le dolía reconocer que sería vencido, que su maravilloso cuerpo se iba a desintegrar [...]" (24-25). En el invierno de 1987, de acuerdo con la propia Badías, Arenas comenzó a desaparecer por largos periodos, a inventar viajes y a mentir. Jaime Manrique en una visita a Reinaldo Arenas, se refiere a la transformación de su cuerpo: "[l] a puerta se abrió y ahogué un grito de asombro. Los atractivos rasgos de Reinaldo estaban horriblemente deformados: media cara se veía hinchada, morada, casi quemada, como si estuviera a punto de caerse" (117). La compulsión por materializar el archivo de Princeton coincide con la progresiva desaparición del cuerpo de Reinaldo, el sida -condición que también une a estos dos escritores- marcará una temporalidad en el 
archivo de Reinaldo. En su carta de despedida, escribe: "En los últimos años, aunque me sentía muy enfermo, he podido terminar mi obra literaria, en la cual he trabajado por casi treinta años. Les dejo pues como legado todos mis terrores $[\ldots]^{\prime \prime}$.

En este aspecto, quiero destacar un movimiento adicional que señala Malabou. La filósofa francesa entiende la filosofía de Hegel como reemplazamiento; es decir, la forma no se forma más que como posibilidad de ser reemplazada. Malabou dice que esta, la forma, solo tendría identidad si es reemplazable, sustituible, relevable (Plasticidad 94). La narrativa somática con la que Arenas construye su archivo lo vuelve sustituto.

Contra la idea pasiva de que el sujeto recibe forma desde un afuera, Reinaldo Arenas materializa un archivo evitando formas fijas o estáticas. Para ello, diseña toda una compleja tecnología que permite que el archivo crezca de manera póstuma. Y esta es una de las particularidades de este archivo. El archivo de Reinaldo Arenas se compone ahora de más piezas (subcolecciones) de todos sus colaboradores y seguidores - traductores, editores, albaceas, amigos, en todo caso, todos conectados por el afecto- que siguen componiendo archivos visuales capaces de reactivar y hacer crecer, con pieles prestadas, el archivo de Arenas. ${ }^{2}$ El archivo y su movimiento continuo, más que proponer una solidificación y, por lo tanto, una subjetivación de la otredad, apunta hacia una destitución de la subjetividad. Incluso el archivo, como sustituto del cuerpo, apela a otras estrategias. Más que cuerpo o un cuerpo sin órganos, se trata de órganos sin cuerpo. Jean-Luc Nancy apunta: "no hay totalidad de cuerpo o más bien de una no hay unidad sintética. Hay piezas, zonas, fragmentos. Hay un pedazo después del otro, un estómago, una ceja, una uña de pulgar, un hombro, un seno, una nariz, un intestino delgado, un canal colédoco, un páncreas" (27-28).

2 Luego de la muerte del escritor, tanto sus amigos del Mariel como sus colaboradores más cercanos han engrosado paulatinamente la colección e incluso se han creado, asociadas a ella, nuevas colecciones. En relación con estas colecciones asociadas, la Biblioteca de Princeton alberga las colecciones de Liliane Hassen y Dolores Kosch; ambas, donadas por traductoras de la obra de Reinaldo Arenas - Kosch al inglés, Hassen al francés - incluyen documentos, cartas, fotografías, borradores inéditos, así como otros documentos relacionados con sus derechos de autor y trámites de publicación póstuma de su obra. En cuanto a los materiales que han ido añadiéndose a la colección, están documentos importantes, como es el caso de los originales usados para la publicación del libro A la sombra del mar, de Juan Abreu, así como fotografías, correspondencia y postales enviadas por el propio Reinaldo Arenas. 
En este sentido, Reinaldo hace que el cuerpo se vuelva extraño para mudar de piel. Al depositar la fotografía, las fotografías, Reinaldo hace de su cuerpo, un cuerpo postergado, como propone Nancy, un extraño cuerpo extraño.

Toco nuevamente la fotografía de la piel de Reinaldo y me doy cuenta de que estoy tocando su piel (figura 7). Ya que al tocar, como cuando se produce la excritura de Nancy, una mano ajena se desliza sobre la mano que toca. Los libros de Reinaldo que piden visitar el archivo también piden activar el archivo al tocarlo (figura 8), ya que al tocar las pieles del archivo se vuelven las pieles de Reinaldo. Es decir, aquello que yo veía como una performance que enviaba a los lectores de los libros al archivo para verificar que los originales no existen, también se puede pensar como una solicitud de tocar. Y tocar el archivo es tocar a Reinaldo en cuanto a que toco lo que Reinaldo Arenas alguna vez tocó. Yo lo toco ahora, en Princeton, con esta mano, con estas manos. Este movimiento táctil ejecutado sobre el archivo epidérmico constituye la única posibilidad material de Reinaldo Arenas.

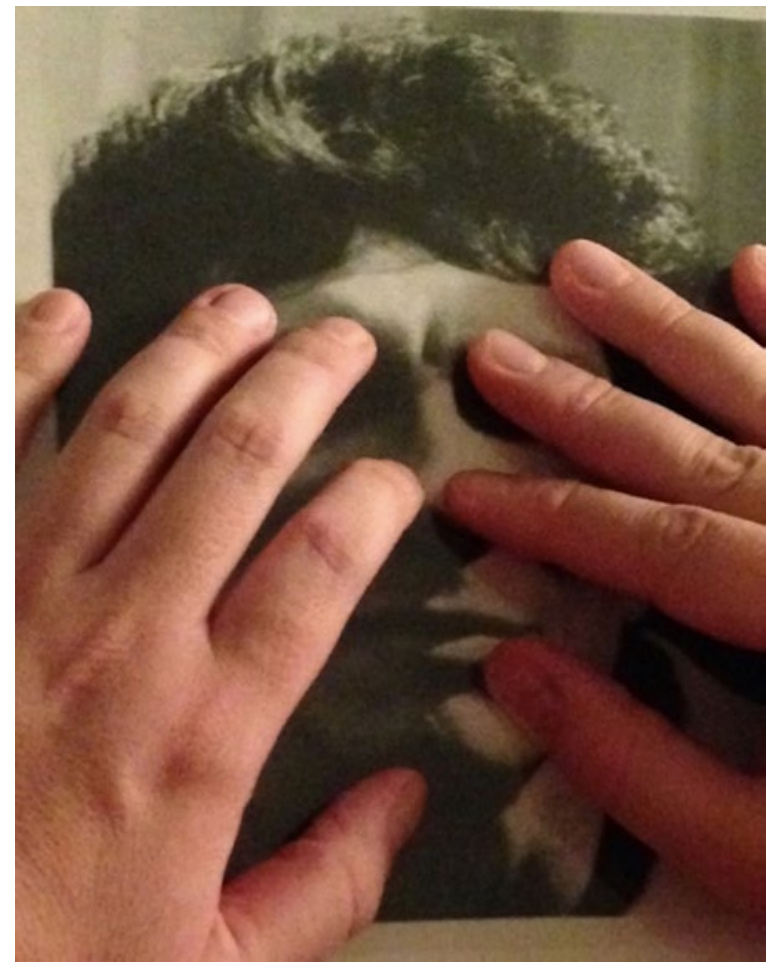

Figura 7. Mis manos tocan la piel de la foto. Fotografía de Javier Guerrero. Princeton, 2013. Reinaldo Arenas Papers, Box 27 Folder 3; Manuscripts Division, Department of Rare Books and Special Collections, Princeton University Library. 


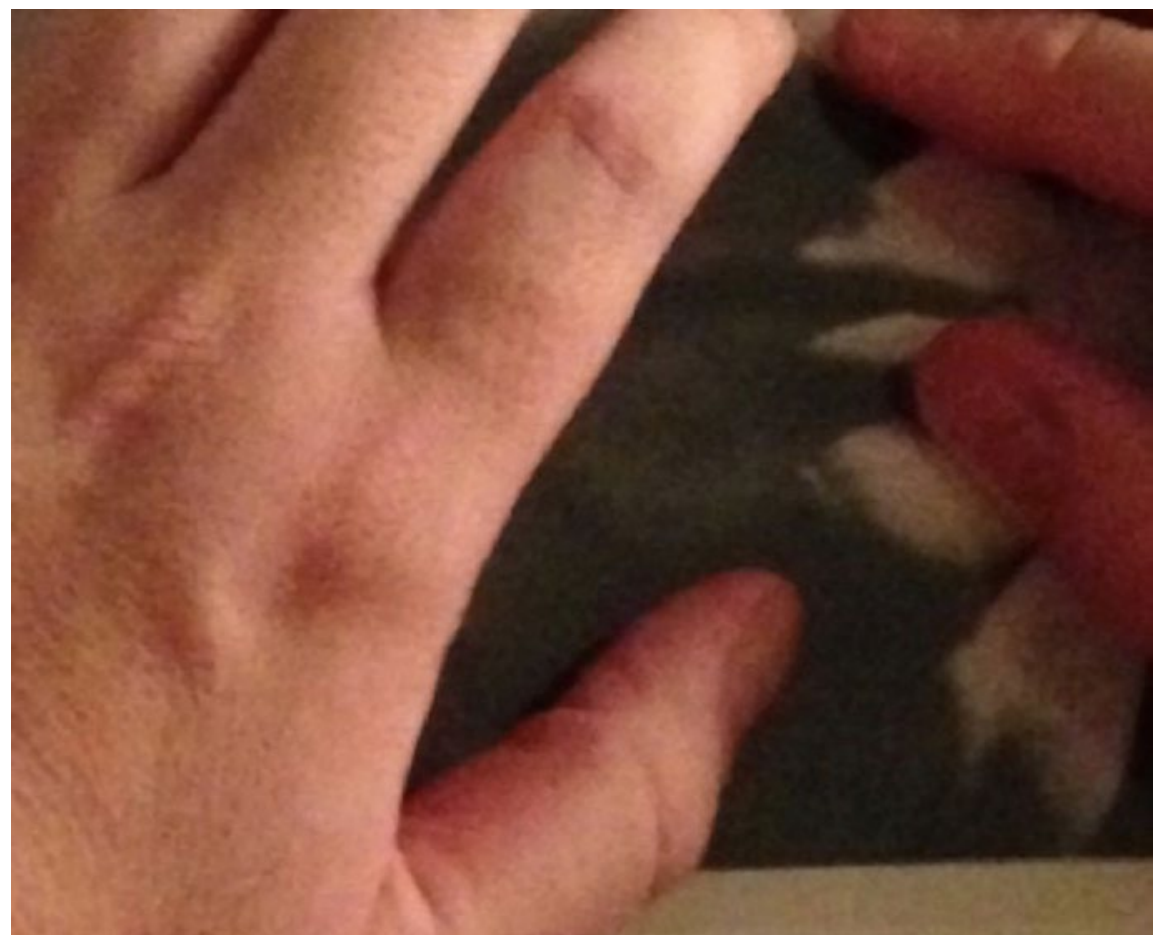

Figura 8. Mis manos tocan la piel de la foto. Fotografía de Javier Guerrero. Princeton, 2013. Reinaldo Arenas Papers, Box 27 Folder 3; Manuscripts Division, Department of Rare Books and Special Collections, Princeton University Library.

El archivo de Reinaldo en la Universidad de Princeton se vuelve sustituto en su plasticidad. Quizá entonces, al pensar en una destitución de la subjetivad, como la plantea Catherine Malabou, tras la posibilidad de un nuevo materialismo, sea necesario pensar que Reinaldo Arenas, al sustituir su cuerpo con el archivo, no propone el reemplazamiento de un cuerpo por otro, sino la destitución y por lo tanto la sustitución del cuerpo por los pliegues del archivo, por una piel de archivo. Reinaldo, transformado en una colección de pieles: toda una cirugía plástica. Pensar la visualidad y la plasticidad de archivo en este aspecto no sería tocar con la mirada, como empieza Derrida su disertación sobre Nancy, El tocar, fean Luc-Nancy, sino más bien un movimiento más radical (figura 9): ir de los ojos a las manos, cambiar los ojos por las manos, los ojos en las manos. Con mis manos tocando su piel, Reinaldo se toca a sí mismo. 


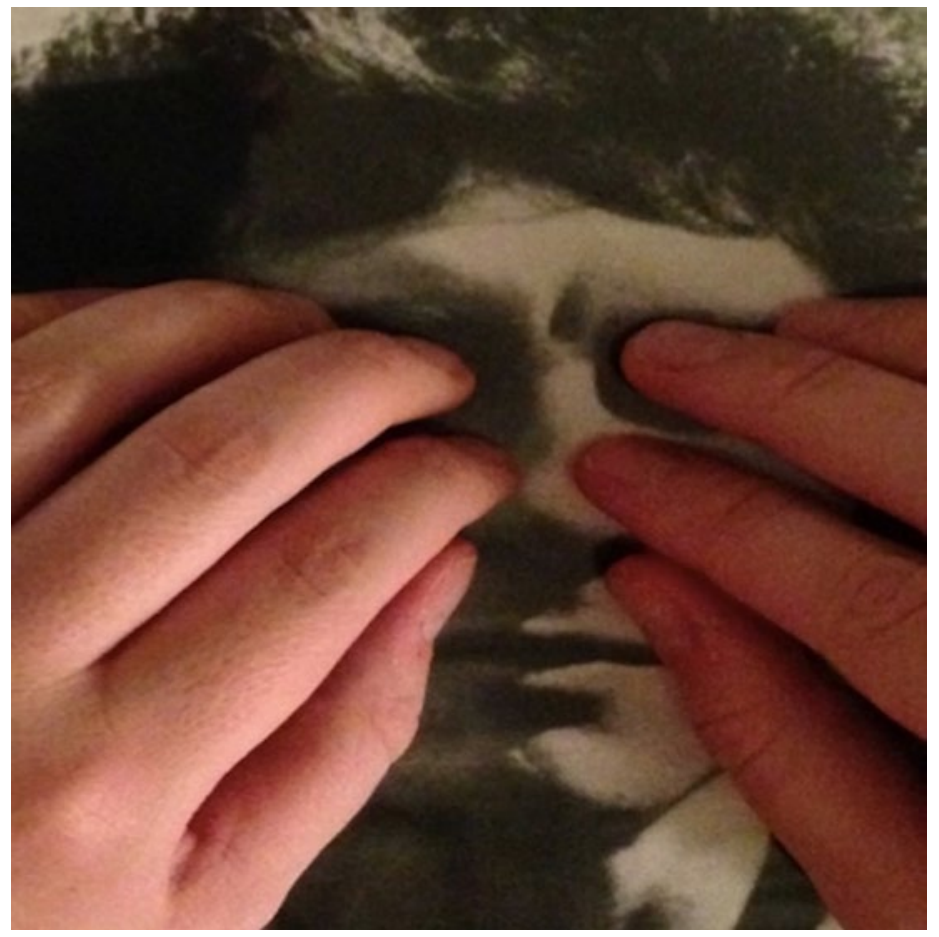

Figura 9. Mis manos tocan la piel de Reinaldo. Fotografía de Javier Guerrero. Princeton, 2013.

Reinaldo Arenas Papers, Box 27 Folder 3; Manuscripts Division, Department of Rare Books and Special Collections, Princeton University Library.

\section{Obras citadas}

Abreu, Juan. A la sombra del mar. Barcelona: Editorial Casiopea, 1998. Impreso.

Arenas, Reinaldo. Antes que anochezca. Barcelona: Tusquets, 2001. Impreso.

Arenas, Reinaldo. Celestino antes del alba. Miami: Universal

(Colección Caniquí), 2001. Impreso.

Arenas, Reinaldo. El mundo alucinante. Caracas: Monte Ávila, 1982. Impreso.

Arenas, Reinaldo. Qué dura es la vida. Novela inédita, 1959, Reinaldo Arena's

Papers, Caja 13a, Firestone Library, Princeton University. Impreso.

Badías, María. "Lo que compartimos con Reinaldo Arenas". Reinaldo Arenas:

recuerdo y presencia. Ed. Reinaldo Sánchez. Miami: Universal, 1994. Impreso.

Barthes, Roland. Fragmentos de un discurso amoroso. Trad. Eduardo

Molina. Buenos Aires: Siglo XXI, 2002. Impreso.

Derrida, Jacques. El tocar, Zean-Luc Nancy. Trad. Horacio Óscar Pons.

Buenos Aires: Amorrortu (Colección Filosofía), 2011. Impreso. 
Derrida, Jacques. Mal de archivo. Trad. Paco Vidarte. Madrid: Trotta, 1997. Impreso.

Derrida, Jacques. "Preface". The Future of Hegel: Plasticity, Temporality, and

Dialectic. Trad. Lisabeth During. New York: Routledge, 2005. Impreso.

Guerrero, Javier. Tecnologías del cuerpo. Exhibicionismo y visualidad en América

Latina. Madrid - Frankfurt: Iberoamericana - Vervuert, 2014. Impreso.

Malabou, Catherine. La plasticidad en espera. Trads. Cristóbal Durán

y Manuela Valdivia. Santiago: Palinodia, 2013. Impreso.

Malabou, Catherine. The Future of Hegel: Plasticity, Temporality, and Dialectics.

Trad. Lisabeth During. New York: Routledge, 2005. Impreso.

Malabou, Catherine. "The Future of Hegel: Plasticity, Temporality,

Dialectic". Hypatia 15.4 (2000): 196-220. Impreso.

Manrique, Jaime. Maricones eminentes. Madrid: Editorial Síntesis, 2000. Impreso.

Nancy, Jean-Luc. Corpus. Trad. Patricio Bulnes. Madrid: Arena Libros, 2003. Impreso.

Sarduy, Mercedes y Severo Sarduy. Cartas a mi hermana en La Habana.

Coral Gables: Severo Sarduy Cultural Foundation, 2013. Impreso.

Sarduy, Severo. "Escrito sobre un cuerpo". Obras Completas.

México: Conaculta, 1999. Impreso.

Sarduy, Severo. La simulación. Caracas: Monte Ávila, 1982. Impreso.

Sarduy, Severo. "Maitreya". Obras Completas. México: Conaculta, 1999. Impreso.

Schnabel, Julian. Dir. Before Nigth Falls. El Mar Pictures - Grandview Pictures, 200o. Filme. 